\title{
Magnetite nanoparticles coat around activated $\gamma$-alumina spheres: A case of novel protection of moisture-sensitive materials against hydration
}

\author{
Jaroslav Kupčík ${ }^{1,2}$ Petr Mikysek ${ }^{3,4}$ Dana Pokorná ${ }^{1}$ Radek Fajgar $^{1}$ Petra Cuřínová ${ }^{1}$ \\ Karel Soukup ${ }^{1}$ Josef Pola $^{1^{*}}$
}

\begin{abstract}
Protection of various materials against hydration is of continuing interest to chemists and material scientists. We report on stabilization of porous surface of activated $\gamma$-alumina spheres (AAS) against hydration by an adhesive coat of nano-magnetite particles. The nano- $\mathrm{Fe}_{3} \mathrm{O}_{4}$-coated AAS were prepared in the ultrasound-agitated suspension of magnetite nanoparticles in heptane and were characterized by using X-ray diffraction, scanning electron microscopy (SEM), transmission electron microscopy (TEM), BET surface area analysis and X-ray photoelectron spectroscopy (XPS). It is deduced that nanoparticle-alumina bonding interaction in non-polar organic solvent is enhanced by van der Waals attractive forces and that sonication induces changes in alumina morphology only in regions of contact between alumina and magnetite nanoparticles. The coated AAS submerged in still water avoid hydration and remain permeable by small gaseous $\left(\mathrm{N}_{2}\right)$ molecules, while those soaked in moving water lose part of their coat and undergo hydration. The pristine and the coated AAS were briefly compared for their ability to degrade model antibiotics by using LC-MS analysis. It is confirmed that the degradation of trimethoprim is more efficient on the coated AAS. Our results are challenging for further research of Coulombic interactions between nano-particles and appropriate solid supports.
\end{abstract}

Keywords: protection against hydration, activated alumina, magnetite nanoparticles, Coulombic interaction, non-polar solvents

\section{Introduction}

Protection against hydration of water-instable particles, molecules and surfaces is of lasting interest and has been explored in stabilization of these entities in biological and colloidal systems, ${ }^{[1,2]}$ dyes $^{[3,4]}$ and pigment useful extenders or fillers ${ }^{[5]}$. It was also recognized in reversible hydration-dehydration equilibria of heteroaromatic molecules ${ }^{[6,7]}$ and it is of common use in stabilization of various surfaces by chemical coating with water-repellent reagents, vapor and laser deposition and

Received: April 23, 2019 Accepted: May 6, 2019 Published: May 8, 2019

* Correspondence to: Josef Pola, Institute of Chemical Process Fundamentals of the Czech Academy of Sciences, Rozvojova 135, 16502 Prague 6, Czech Republic; Email: pola@icpf.cas.cz

1 Institute of Chemical Process Fundamentals of the Czech Academy of Sciences, Rozvojova 135, 16502 Prague 6, Czech Republic

${ }^{2}$ Institute of Inorganic Chemistry of Czech Academy of Sciences, Husinec-Rez 1001, 25068 Rez, Czech Republic
Institute of Inorganic Che

${ }^{3}$ Institute of Geology of the Czech Academy of Sciences, Rozvojová 269, 16500 Praha 6, Czech Republic

${ }^{4}$ Institute of Geological Sciences, Faculty of Science, Masaryk University, Kotlářská 2, 61137 Brno, Czech Republic

Citation: Kupčík J, Mikysek P, Pokorná D, et al. Magnetite nanoparticles coat around activated $\gamma$-alumina spheres: A case of novel protection of moisture-sensitive materials against hydration. Chem Rep, 2019, 1(2): 67-76.

Copyright: (c) 2019 Josef Pola, et al. This is an open access article distributed under the terms of the Creative Commons Attribution License, which permits unrestricted use, distribution, and reproduction in any medium, provided the original author and source are credited. sputtering methods. ${ }^{[8-10]}$ Other examples of stabilization against hydration relate to sesquioxides of the lanthanide series like $\mathrm{Nd}_{2} \mathrm{O}_{3}$ stabilized through sintering with added metal oxide dopants (particularly $\mathrm{Y}_{2} \mathrm{O}_{3}$ and $\mathrm{TiO}_{2}$ ). ${ }^{[11,12]}$

The past two decades have witnessed an enormous use of physical processes (e.g. magnetron sputtering, laser or plasma deposition, atomic oxygen-assisted MBE) through which large inorganic bodies become extensively coated with high-energy species in vacuum and the produced coats are preserved when exposed to air, organic solvent and even aqueous phase. These processes do not appear to be accompanied by low-cost coating procedures involving weak van der Waals interactions between surface and nanoparticles in liquid phases, although future science may solve tasks related to weak interactions between surface and nanoparticles in these media. Such interactions are affected by structure and stability of interacting species in a given liquid phase; it is known that bonding between nanoparticles and surface is affected by the extent of their solvation, nanoparticles mobility in the aquatic media is highly restricted by their aggregation and the stability of the surface may be influenced by hydration leading to different surface structures. 
Such limitations preclude coating of moisture sensitive materials by nanoparticles in water and in liquid polar organic compounds. Thus, the activated $\gamma$ alumina (used as desiccant or catalyst ${ }^{[13]}$ ) is a hygroscopic porous amphoteric substance and its easy hydration has an important influence on its surface reactivity and sorption properties. It modifies ${ }^{[14-17]}$ inner and surface areas and leads to transformations decreasing surface density of unsaturated coordination sites, finally yielding bayerite $\left(\beta-\mathrm{Al}(\mathrm{OH})_{3}\right)$. The known formation of hydration layers and chemical sorption (coordination of polar methanol, acetonitrile and aromatic (toluene) organic solvents) on alumina surface ${ }^{[14,15]}$ are detrimental for nanoparticle-surface interaction.

In this paper we show that anhydrous surface of porous activated $\gamma$-alumina becomes stabilized against hydration in water by ultrasound-assisted coating with nanosized magnetite particles in liquid alkanes and propose that this process can find use in the formation of protective shells of other metal oxide nanoparticles around surfaces of alumina-based and/or other moisture-sensitive materials.

\section{Materials and methods}

The AAS (KA404, 3-5 mm o. d., Jiangxi Xintao Technol. Co.) were dried in a vacuum at $200^{\circ} \mathrm{C}$. The magnetite nanopowder $(0.05 \mathrm{~g}$, Aldrich, $50 \mathrm{~nm})$ was dispersed into in $50 \mathrm{ml}$ of heptane or hexane (Merck, acs p.a.) in a $100 \mathrm{ml}$ Erlenmayer flask which was shaken in an ultrasonic Tesla $(300 \mathrm{~W})$ bath for $10 \mathrm{~min}$. Thereafter, the AAS (40 g) were added and the mixture was agitated with ultrasound for additional $10 \mathrm{~min}$. The white spheres turned black and were separated on a nutch filter, rinsed with heptane and dried in air at room temperature. The coating procedure is illustrated in Figure 1 and cannot be accomplished in polar solvents (water or ethanol) where AAS retain their white appearance.

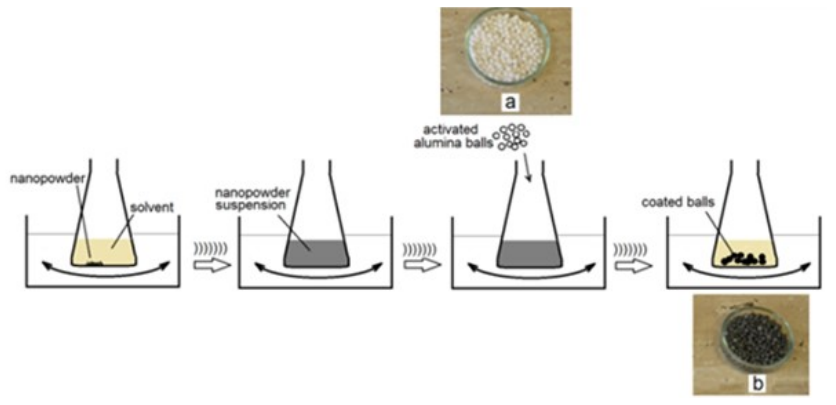

Figure 1. Scheme of ultrasonic coating of white AAS (a) in n-heptane producing black $\mathrm{Fe}_{3} \mathrm{O}_{4}$-coated AAS (b)

The rigidity of the nano-magnetite coat in water was tested for the spheres submerged in deionized (DEI) wa- ter in an unmoving and a shaken flask for different spans of time (2-4 h) and also for the spheres packed in a glass column exposed to up-flow of water controlled with a peristaltic pump. After such washing, the spheres were carefully withdrawn and dried at $40^{\circ} \mathrm{C}$ in air. These washed spheres and those coated in heptane were examined for their structure by XRD and BET surface analyses and by SEM, TEM and XPS techniques. The washed spheres were also tested for their ability to degrade antibiotics.

The samples of pristine and coated AAS were applied for XRD analyses after dry crushing on a steel plate and pulverizing to a very fine powder in liquid heptane using a corundum mill. Approximately 5-10 $\mathrm{mg}$ of the fine powder was mixed with heptane into a suspension and applied on a silicon plate. X-ray powder diffraction investigation was carried out with a Bruker D8 Discover diffractometer equipped with a silicon-strip linear LynxEye detector and a focusing germanium primary monochromator of Johansson type providing $\mathrm{Cu} K \alpha$ radiation $(\lambda=1.54056 \AA)$. Data for mineral identification were collected in the $2 \theta$ range of $5-90^{\circ}$ with a step size of $0.016^{\circ}$ and a counting time of 0.7 second at each step, and detector angular opening of $2.896^{\circ}$. The phase identification was performed with Diffrac.Eva software v4.2.2 and ICDD PDF-2 database (Bruker AXS GmbH, Karlsruhe, Germany; 2011-2016). Semi-quantitative estimation of the mineral composition was calculated by the reference intensity ratio method implemented in Diffrac.Eva software.

Scanning electron microscopy images of the powdered AAS were recorded with a SEM Tescan Indusem (Bruker Quantax) microscope equipped with an EDAX detector. Transmission electron microscopy (TEM) measurements on the samples scraped from the $\mathrm{Fe}_{3} \mathrm{O}_{4}$-coated AAS were performed on a JEOL JEM 3010TEM microscope equipped with an EDS detector (INCA/Oxford) and CCD Gatan (Digital Micrograph software). The sample was dispersed in isopropanol, treated in ultrasound and a drop of very dilute suspension was placed on a holey-carbon coated $\mathrm{Cu}$-grid and allowed to dry by evaporation at ambient temperature. Electron diffraction patterns were evaluated using JCPDS PDF-4 database ${ }^{[18]}$ and the Process Diffraction software package ${ }^{[19]}$.

The BET surface, the mesopore surface area and the micropore volume were evaluated from the nitrogen physical adsorption-desorption isotherms measured at $77 \mathrm{~K}$ obtained with the ASAP2020M instrument (Micromeritics, USA).

X-ray photoelectron spectra (XPS) were measured by Kratos ESCA 3400 furnished with a polychromatic 
magnesium X-ray source $(\mathrm{Mg} \mathrm{K} \alpha$ radiation, energy $1253.4 \mathrm{eV}, 120 \mathrm{~W}$ ) at base pressure kept at $5.010^{-7} \mathrm{~Pa}$. The spectra were fitted using a Gaussian-Lorentzian line shape and the Shirley background was subtracted. Survey spectra between $0-1000 \mathrm{eV}$ were collected with incremental step $0.2 \mathrm{eV}$ and more detailed narrow spectra were taken over $\mathrm{Al} 2 \mathrm{p}, \mathrm{Fe} 2 \mathrm{p}, \mathrm{O}$ 1s and $\mathrm{C} 1 \mathrm{~s}$ regions with the incremental steps $0.05 \mathrm{eV}$. Pass energy of $25 \mathrm{eV}$ with corresponding energy resolution $0.8 \mathrm{eV}$ was used for acquisition of high resolution spectra. The samples were mildly sputtered with $\mathrm{Ar}^{+}$ions at $1.0 \mathrm{kV}$ with current of $10 \mu \mathrm{A}$ for $90 \mathrm{sec}$ to remove superficial layers. Spectra were calibrated to $\mathrm{C} 1 \mathrm{~s}$ line centered at $284.8 \mathrm{eV}$. The position of samples was fixed by a double-sided carbon tape. The inner layer of the magnetite coat on the AAS was exposed for the measurement after wiping off the outer layers by a threefold attachment of the adhesive carbon tape.

The depletion of a mixture of antibiotics (ATB) - trimethoprim (TMP), sulfamethoxazole (SMX) and azithromycine (AZM) - (all purchased from Aldrich) was monitored by LC-MS spectroscopy in mildly shaken 20 $\mathrm{ml}$ vessels containing $3 \mathrm{~g}$ of the pristine or nano- $\mathrm{Fe}_{3} \mathrm{O}_{4}$ coated AAS soaked in $10 \mathrm{ml}$ of ATB (150-200 $\mu \mathrm{g} / \mathrm{L})$ in DEI water or $0.2 \mathrm{M} \mathrm{H}_{2} \mathrm{O}_{2}$ solution. Care was taken to avoid abrasion of the magnetite shell and then 0.1 $\mathrm{ml}$ aliquots of the ATB solutions were withdrawn for the analysis in one hour periods. The LC/MS spectroscopy was performed on a Dionex UltiMate3000 instrument with a MicroTOF-QIII mass detector (Bruker) and Luna $\mathrm{C} 18$ Phenomenex column using $\mathrm{CH}_{3} \mathrm{CN} / \mathrm{DEI}$ $\mathrm{H}_{2} \mathrm{O} / \mathrm{HCOOH}(0.1 \%)$ phase. The HRMS spectra with electrospray ionization were collected in positive ion mode. The TMP degradation $(1 \mathrm{mg} / \mathrm{L})$ in shaken $0.2 \mathrm{M}$ $\mathrm{H}_{2} \mathrm{O}_{2}$ solution containing both pristine and coated AAS washed in DEI water were carried out as above and the $\mathrm{m} / \mathrm{z}$ lines of degradation fragments, monitored through using direct inlet ( $5 \mathrm{~min}$ flow at $180 \mu \mathrm{L} / \mathrm{h}$ rate), were assessed as average of 5 intensity values.

\section{Results and discussion}

Soaking of the dried AAS in the ultrasound agitated suspension of nano-magnetite powder in heptane leads to a fast color change of these spheres which turn black due to a continuous nano-magnetite coat developed around them. The black coat formation is a consequence of ultrasound-induced dispersion and de-agglomeration of the added (initially agglomerated) $\mathrm{Fe}_{3} \mathrm{O}_{4}$ nanoparticles in the course of their attachment to alumina surface. This effect can operate in synergy with cavitational erosion of alumina surface. We assume that the coat is developed owing to strong attraction forces between poorly alkanesolvated nano-magnetite particles and activated alumina surface, since no such color change is observed in polar solvents like ethanol or water, wherein AAS retain their white appearance. The coat is rigid in still and moving alkanes and also in still water. However, some nanomagnetite particles of the coat are released to moving (shaken of flowing) water (Figure 2).

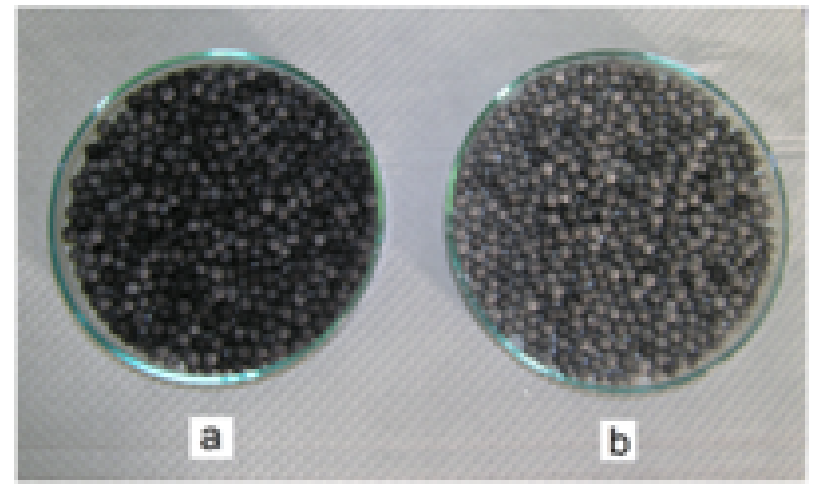

Figure 2. $\mathrm{Fe}_{3} \mathrm{O}_{4}$-coated AAS obtained in heptane before (a) and after (b) washing in moving water

It is now a common view that surfaces of high temperature-activated $\gamma$-alumina ${ }^{[16,20]}$ and dry magnetite $^{[21,22]}$ possess coordinatively unsaturated $\mathrm{Al}, \mathrm{Fe}$ and oxide sites which behave as the Lewis acids and bases. These oxides can interact in nonpolar solvents (alkanes) through a specific (dipole-dipole or coordinative) Al-O...Fe-O bonding which is stronger than Fe$\mathrm{O}$... Fe-O bonding leading to agglomeration. Amphoteric $\mathrm{Al}_{2} \mathrm{O}_{3}$ and $\mathrm{Fe}_{3} \mathrm{O}_{4}$ surfaces sunk in water are modified by dissociative chemisorption of $\mathrm{H}_{2} \mathrm{O}$ on Lewis acidic sites forming $\mathrm{Al}-\mathrm{OH}$ and $\mathrm{Fe}-\mathrm{OH}$-bonds and develop different surface charge. In pure water, $\mathrm{pH}$ is close to magnetite point of zero charge $(\mathrm{pzc}=6-6.8)^{[22]}$ and within the alumina pzc values $6-9$ depending ${ }^{[16]}$ on surface heterogeneity (modes of alumina preparation). At $\mathrm{pH}=7$, the alumina and magnetite surfaces develop low positive surface charges (net proton surface excess $^{[23]}$ ) which spread on their aqueous shells and will bring about repulsive interaction between both hydrated species. Thus, owing to the solvation by $\mathrm{H}_{2} \mathrm{O}$ molecules, these hydrated species become separated, since hydration-induced repulsion overwhelms attractive forces between the naked species in alkane.

The obvious reason for some loss of the $\mathrm{Fe}_{3} \mathrm{O}_{4}$ nanoparticles in moving water is kinetic energy of water molecules colliding with outer layers of the coat. These outer layers are composed of weakly-bonded agglomerated nanoparticles which become coordinated to water, may form $\mathrm{Fe}-\mathrm{OH}$ bonds and release to aqueous phase. 


\section{1 $\mathrm{Fe}_{3} \mathrm{O}_{4}$-coated $\mathrm{AAS}$ in still water}

The XRD analysis of the dry AAS, nano- $\mathrm{Fe}_{3} \mathrm{O}_{4}$ coated AAS and AAS soaked in still water allows discern differences in their crystal structure (Figure 3). Broad and low intensity diffraction bands of the dried AAS relate to small crystalline dimensions of Aluminum Oxide (e.g. PDF 04-0880 and Boehmite $\mathrm{AlO}(\mathrm{OH}) \mathrm{PDF} 74-$ 1871). These two crystalline structures are unavoidably accompanied by minor contributions of other forms of activated $\gamma-\mathrm{Al}_{2} \mathrm{O}_{3}{ }^{[18,24]}$ which have similar diffraction patterns.

Submerged in still DEI water, the AAS reveal diffraction bands of Bayerite $\left(\mathrm{Al}(\mathrm{OH})_{3}, \mathrm{PDF} 74-1119\right)$ and an amorphous phase at the $2 \Theta$ range $12-16^{\circ}$. These features prove easy hydration ${ }^{[14]}$. The $\mathrm{Fe}_{3} \mathrm{O}_{4}$-coated AAS submerged in still water for 1 day up to 1 month possess diffraction pattern which is virtually identical to that of the dried AAS. The pattern shows neither diffraction lines of Bayerite $\left(\mathrm{Al}(\mathrm{OH})_{3}\right)$, nor the broad band at 12$16^{\circ}$. This confirms that the nano- $\mathrm{Fe}_{3} \mathrm{O}_{4}$ coat provides efficient protection of the AAS against hydration. We note, however, that the relative intensity of the diffraction line of Boehmite $\mathrm{AlO}(\mathrm{OH})$ at $2 \Theta 14.45^{\circ}$ in the coated samples submerged in DEI water for 1 day, 1 week and 1 month $(33,42$ and 42, respectively) is higher than that for the dried activated alumina sample (27), which may indicate an extraordinarily slow penetration of water through the nano-magnetite coat and an insignificant hydration of alumina surface.

More understanding of porous structures of the pristine and $\mathrm{Fe}_{3} \mathrm{O}_{4}$-coated AAS submerged in water is gained from their texture analyses (Table 1). It is seen that the BET surface area $\left(\mathrm{S}_{B E T}\right)$, the mesopore surface area $\left(\mathrm{S}_{\text {meso }}\right)$ and the micropore volume $\left(\mathrm{V}_{\text {micro }}\right)$ of the pristine AAS before and after soaking into water are little different: the soaked alumina possesses slightly higher $\mathrm{S}_{B E T}$ and somewhat lower $\mathrm{S}_{\text {meso }}$ and $\mathrm{V}_{\text {micro }}$ values. It is known that hydration of porous aluminas into bayerite is accompanied by a slight increase ${ }^{[14]}$ or decrease $^{[17]}$ of BET surface area, the latter being due to accretion of hydrated alumina leading to pores filling. The observed $\mathrm{V}_{\text {micro }}$ and $\mathrm{S}_{\text {meso }}$ values thus reflect reduction of hydrated micro and meso-regions and suggest that that the larger pores do not spall. As for the $\mathrm{Fe}_{3} \mathrm{O}_{4}$ coated AAS soaked in still water, their $\mathrm{S}_{B E T}, \mathrm{~S}_{\text {meso }}$ and $\mathrm{V}_{\text {micro }}$ values slightly decrease, which indicates that the $\mathrm{Fe}_{3} \mathrm{O}_{4}$ coat of the AAS does not restrict passage of small $\left(\mathrm{N}_{2}\right)$ molecules. The small decrease in the $\mathrm{S}_{B E T}$ value is likely due to the nano- $\mathrm{Fe}_{3} \mathrm{O}_{4}$ nanoparticles agglomerating on the alumina surface.

The SEM images of the pristine and the $\mathrm{Fe}_{3} \mathrm{O}_{4}$-coated AAS confirm that they are morphologically similar ma- terials with rough surface and irregular cavities (Figure 4). The EDX analysis of the coated AAS shows the presence of both $\mathrm{Al}$ and $\mathrm{Fe}$ whose atomic $\% \mathrm{Fe} / \mathrm{Al}$ ratios for large (up to $300 \mu \mathrm{m}$-sized) and small (several $\mu \mathrm{m}$-sized) areas are respectively ranging at 1.16-2.40 and 0.16-3.40. These different values are in line with variable coat thickness and with EDX elemental mapping at the microstructural level showing uneven $\mu \mathrm{m}$-sized spots of pale red and pale green intensities in different areas of the image.

Table 1. Texture characteristics of pristine and magnetite-coated AAS

\begin{tabular}{|c|c|c|c|}
\hline \multirow{2}{*}{ Sample } & $\mathrm{S}_{B E T}$ & $\mathrm{~S}_{\text {meso }}$ & $\mathrm{V}_{\text {micro }}$ \\
\hline & $\left(\mathrm{m}^{2} / \mathrm{g}\right)$ & $\left(\mathrm{m}^{2} / \mathrm{g}\right)$ & $\left(\mathrm{mm}^{3} / \mathrm{g}\right)$ \\
\hline AAS $^{\text {a }}$ & 285 & 198 & 47 \\
\hline AAS $^{\text {a }}$ soaked in water for 1 day & 301 & 188 & 39 \\
\hline $\mathrm{Fe}_{3} \mathrm{O}_{4}$-coated AAS dried at room temperature & 271 & 195 & 43 \\
\hline $\mathrm{Fe}_{3} \mathrm{O}_{4}$-coated AAS soaked in water for 1 day & 262 & 189 & 38 \\
\hline Nano- $\mathrm{Fe}_{3} \mathrm{O}_{4}$ powder & 6.4 & 3 & 1.8 \\
\hline
\end{tabular}

Note: ${ }^{a}$ treated in vaccum at $200{ }^{\circ} \mathrm{C}$

\section{2 $\mathrm{Fe}_{3} \mathrm{O}_{4}$-coated $\mathrm{AAS}$ in moving water}

The $\mathrm{Fe}_{3} \mathrm{O}_{4}$-coated AAS submerged in moving DEI water or $0.2 \mathrm{M} \mathrm{H}_{2} \mathrm{O}_{2}$-DEI water solution undergo hydration. These washed spheres are still quite dark and possess grey and black patches. Their XRD pattern shows lines of aluminum oxide, Boehmite, Bayerite and Gibbsite (Figure 5). The lines of Bayerite and Gibbsite are little significant for the sample exposed to moving water but pronounced for the sample exposed to moving $\mathrm{H}_{2} \mathrm{O}_{2}$ solution. The higher extent of hydration in $\mathrm{H}_{2} \mathrm{O}_{2}$ solution thus reflects effect of hydrogen peroxide.

The XPS spectra of the dried and hydrated AAS along with the spectra of the $\mathrm{Fe}_{3} \mathrm{O}_{4}$-coated AAS and the washed $\mathrm{Fe}_{3} \mathrm{O}_{4}$-coated AAS are helpful to get more information on surface and interface properties of these species. The stoichiometry of the dried AAS calculated from $\mathrm{Al} 2 \mathrm{p}$ and combined total lattice oxide and hydroxide $\mathrm{O} 1 \mathrm{~s}$ bands shows the atomic ratio $\mathrm{Al} / \mathrm{O}=0.52$, which corresponds to the presence of both oxide $(\mathrm{Al} / \mathrm{O}$ $=0.66)$ and hydroxide $(\mathrm{Al} / \mathrm{O}=0.33)$ forms on the measured surface. The hydrated AAS show the $\mathrm{Al} / \mathrm{O}$ ratio equal to 0.29 corresponding to hydroxide form (Bayerite, as proved by XRD). The $\mathrm{Al} 2 \mathrm{p}$ bands are naturally broad due to closely spaced spin-orbit components and their FWHM are about $1.8 \mathrm{eV}$ for the bulk $\mathrm{Al}_{2} \mathrm{O}_{3}$ and 2.5 $\mathrm{eV}$ for the hydrated aluminium oxide ${ }^{[25]}$. In our spectra, FWHM $2.56 \mathrm{eV}$ is observed for the hydrated AAS and much broader band (FWHM $2.75 \mathrm{eV}$ ) is found for the vacuum dried AAS. This proves that in the sample 


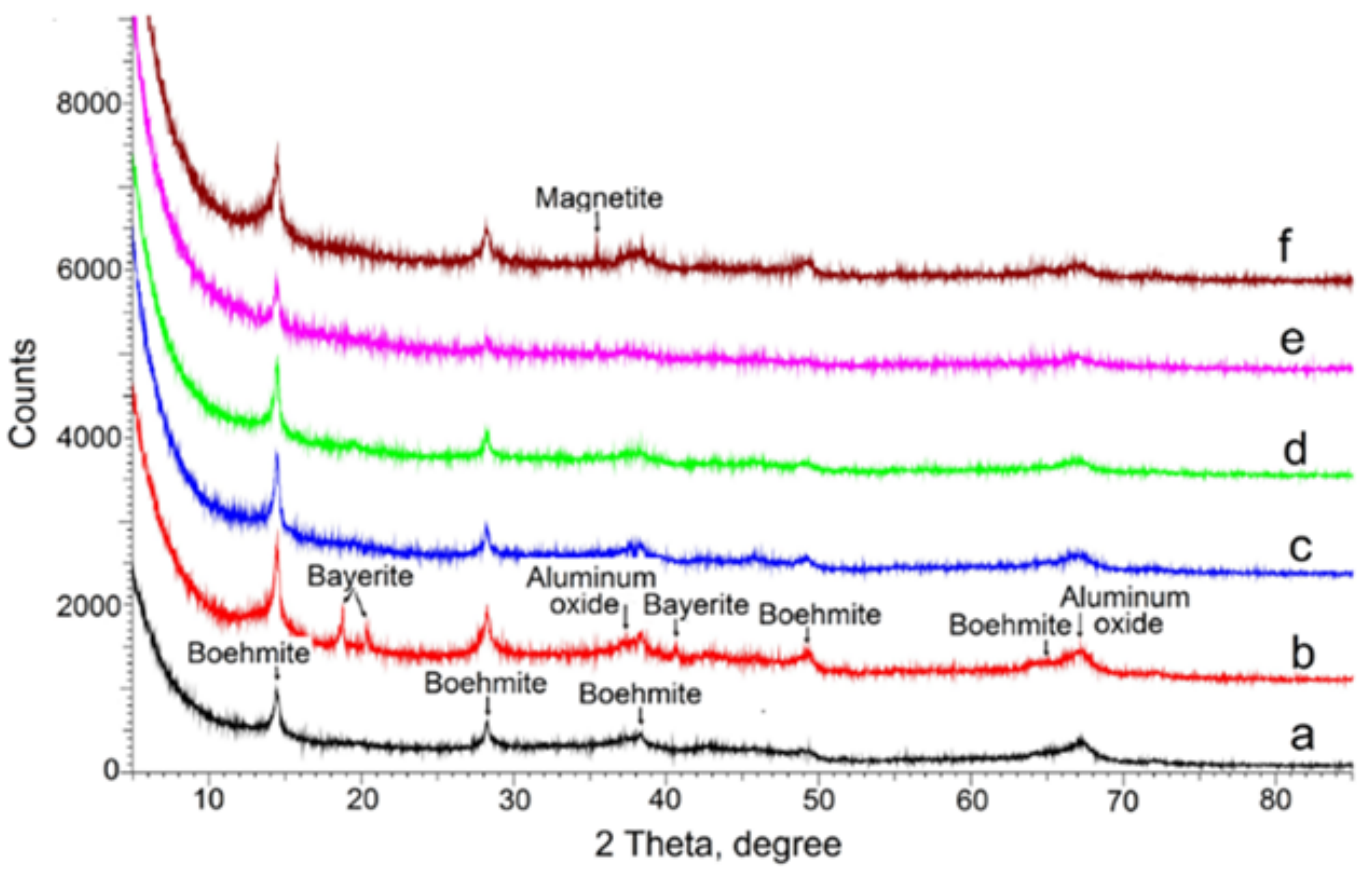

Figure 3. XRD patterns of the dried AAS (a) and the AAS soaked in still water for 1 day (b) compared to the nano-magnetite-coated AAS before (c) and after soaking in water for 1 day (d), 1 week (e) and 1 month (f). Assignment: Aluminum Oxide, PDF\# 04-0880; Boehmite $\mathrm{AlO}(\mathrm{OH}) \mathrm{PDF} \#$ 74-1871; Bayerite, $\mathrm{Al}(\mathrm{OH})_{3}$, PDF\# 74-1119

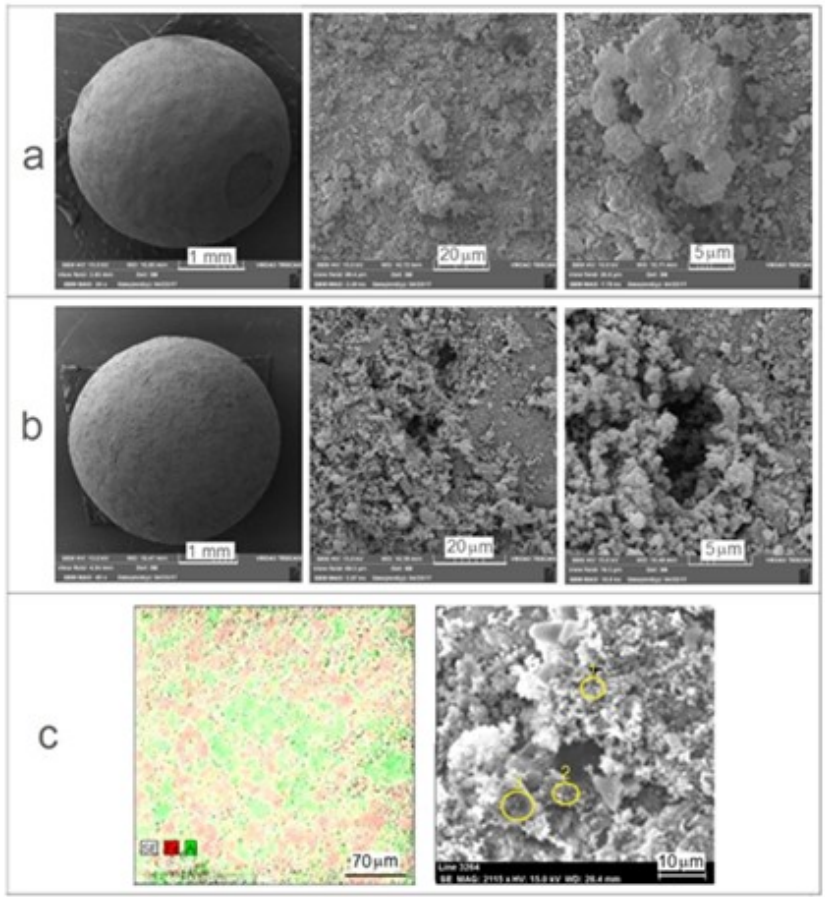

Figure 4. SEM images of pristine (a) and $\mathrm{Fe}_{3} \mathrm{O}_{4}$-coated (b) AAS with examples of elemental mapping and EDX analysis showing at. \% Fe/Al ratio at spots marked $1-3$ as 3.40, 2.65 and 0.16 , respectively with combined oxide/hydroxide forms two bands contribute to the resulting envelope (Figure 6a,6b). The Fe $2 \mathrm{p}$ region of magnetite shows two broad bands due to significantly split spin-orbit components; the Fe $2 \mathrm{p}_{3 / 2}$ band is de-convoluted to $\mathrm{Fe}(2+)$ doublet contributions at 708.3 and $709.2 \mathrm{eV}$ and the multiplet $\mathrm{Fe}(3+)$ band contributions appear between 710.2 and $714.1 \mathrm{eV}^{[26]}$. Exactly this spectral pattern is also observed for the washed $\mathrm{Fe}_{3} \mathrm{O}_{4}$-coated AAS (Figure 6c). The $\mathrm{O}$ 1s spectral regions show main contributions of lattice $\mathrm{Al}-\mathrm{O}(531.8 \mathrm{eV})$ and $\mathrm{Al}-\mathrm{OH}(532.7 \mathrm{eV})$ in the dried AAS sample (Figure $6 \mathrm{~d})$ and a prevailing $\mathrm{Al}-\mathrm{OH}(532.7 \mathrm{eV})$ contribution in the hydrated AAS sample (Figure 7e). The inner layer of the magnetite coat on the spheres of the washed $\mathrm{Fe}_{3} \mathrm{O}_{4}$ coated AAS sample was assessed after successive threefold wiping off outer magnetite layers. The O1s spectra of the "exposed" surface at 531, 532 and $533.7 \mathrm{eV}$ are, in the given order, assigned to signals of Fe-O lattice, $\mathrm{Fe}-\mathrm{OH}$ signals and minor contributions ascribed to $\mathrm{C}-\mathrm{O} / \mathrm{C}=\mathrm{O}$ moieties and/or adsorbed water (Figure $7 \mathrm{f}$ ). Such assignment is in accordance with the observation that only Al-OH $(532.7 \mathrm{eV})$ but not $\mathrm{Al}-\mathrm{O}(531.8 \mathrm{eV})$ can survive on the washed alumina surface and reflects high persistence of the $\mathrm{Fe}_{3} \mathrm{O}_{4}$ nanoparticles bonded to alumina surface.

The SEM-EDX analysis of the $\mathrm{Fe}_{3} \mathrm{O}_{4}$-coated AAS washed in moving water (Figure 7) shows the irregular 


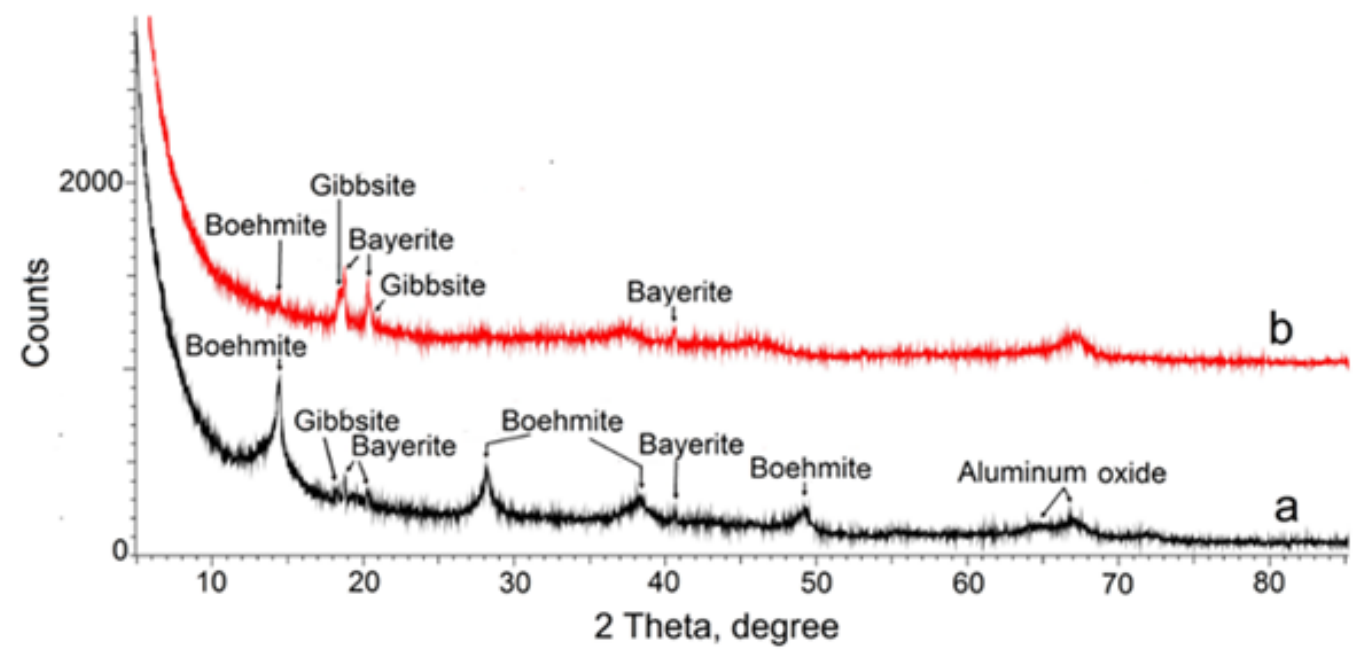

Figure 5. XRD patterns of magnetite-coated AAS mildly shaken in water (a) and in $0.2 \mathrm{M}$ aqueous $\mathrm{H}_{2} \mathrm{O}_{2}$ solution (b) for 6 h. Assignment: Aluminum Oxide, PDF\# 04-0880; Boehmite AlO $(\mathrm{OH}) \mathrm{PDF} \# 74-1871$; Bayerite, $\mathrm{Al}(\mathrm{OH})_{3}, \mathrm{PDF} \# 74-1119 ; \mathrm{Gibbsite}, \mathrm{Al}(\mathrm{OH})_{3}$, PDF\# 12-0460

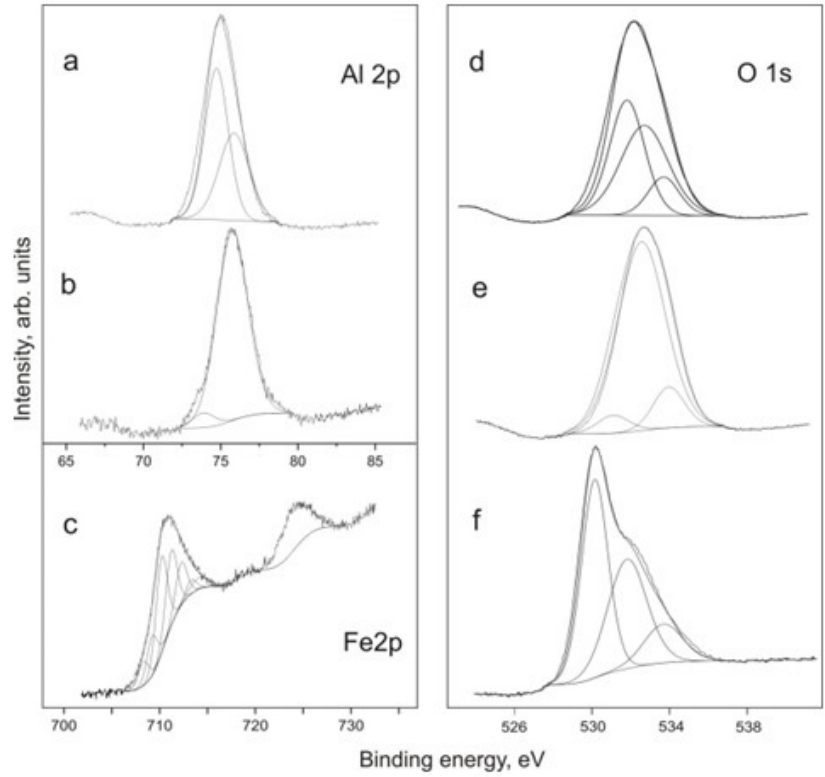

Figure 6. XP spectra of dried (a) and hydrated (b) AAS, Fe 2p spectra of the coated AAS (c) and O 1s spectra of the dried (d) and hydrated (e) AAS and coated AAS (f)

surface with the atomic $\% \mathrm{Fe} / \mathrm{Al}$ ratio for ca. $500 \mathrm{~mm}^{2}$ areas ranging at $0.19-0.34$. These values are lower compared to those for the spheres dwelled in still water and in line with some loss of nano-magnetite particles. The EDX elemental mapping at the microstructural level illustrates that $\mathrm{Fe}_{3} \mathrm{O}_{4}$ occurs as uneven $\mu$ m-sized spots. The different $\mathrm{Fe}$ (red) and $\mathrm{Al}$ (green) color intensities for different areas of the image indicate variable thickness of the coat and hence variable extent of nanomagnetite particles aggregation on different locations of the AAS surface.

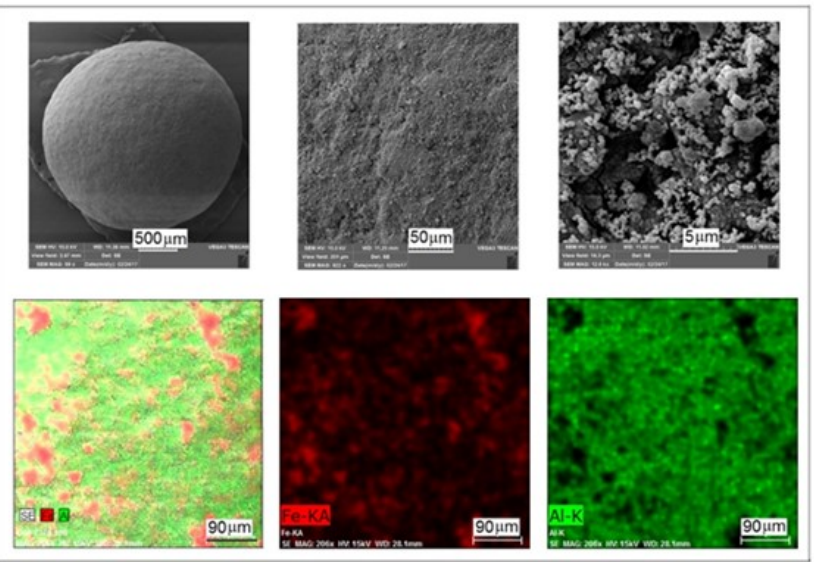

Figure 7. SEM-EDX mapping of washed $\mathrm{Fe}_{3} \mathrm{O}_{4}$-coated AAS

The TEM images, selected area electron diffraction (SAED) and energy dispersive $\mathrm{x}$-ray spectroscopy (EDS) of the samples scratched from the coated AAS exposed to moving water give more details on the interface between alumina and magnetite coat (Figure 8). Both compact dark 100-200 nm-sized $\mathrm{Fe}_{3} \mathrm{O}_{4}$ cubes, either free or stuck to each other, along with brighter porous grainy and shapeless phases are observed prior and after water treatment. The SAED of magnetite cubes manifest spot diffraction patterns consistent with cubic morphology (PdF 72-2303). Diffraction patterns of the brighter phases relate to cubic $\gamma-\mathrm{Al}_{2} \mathrm{O}_{3}$, e.g. PDF 500741. These ca. several hundred $\mathrm{nm}$-sized regions not occurring in the direct contact with $\mathrm{Fe}_{3} \mathrm{O}_{4}$ cubes show, similarly as those of the commercial $\mathrm{Al}_{2} \mathrm{O}_{3}$, a pattern 
of diffuse spots which resemble monocrystal. Such pattern can be ascribed to agglomerates composed of almost identically oriented several ten nm-sized platelets.

The brighter regions occurring in a direct contact with the $\mathrm{Fe}_{3} \mathrm{O}_{4}$ cubes show also diffraction pattern of rings (characteristic for nanoparticle assemblies assigned to $\gamma-\mathrm{Al}_{2} \mathrm{O}_{3}$ (Pdf 50-0741), but have somewhat dissimilar structure which implies that the platelets near $\mathrm{Fe}_{3} \mathrm{O}_{4}$ cubes decay in ultrasound to a number of nm-sized particles. Such explanation is in line with the same change of morphology upon prolonged ultrasound treatment (Figure 9). These data thus conclude that ultrasound treatment induces changes in alumina morphology only in regions of contact between alumina and nanomagnetite entities.

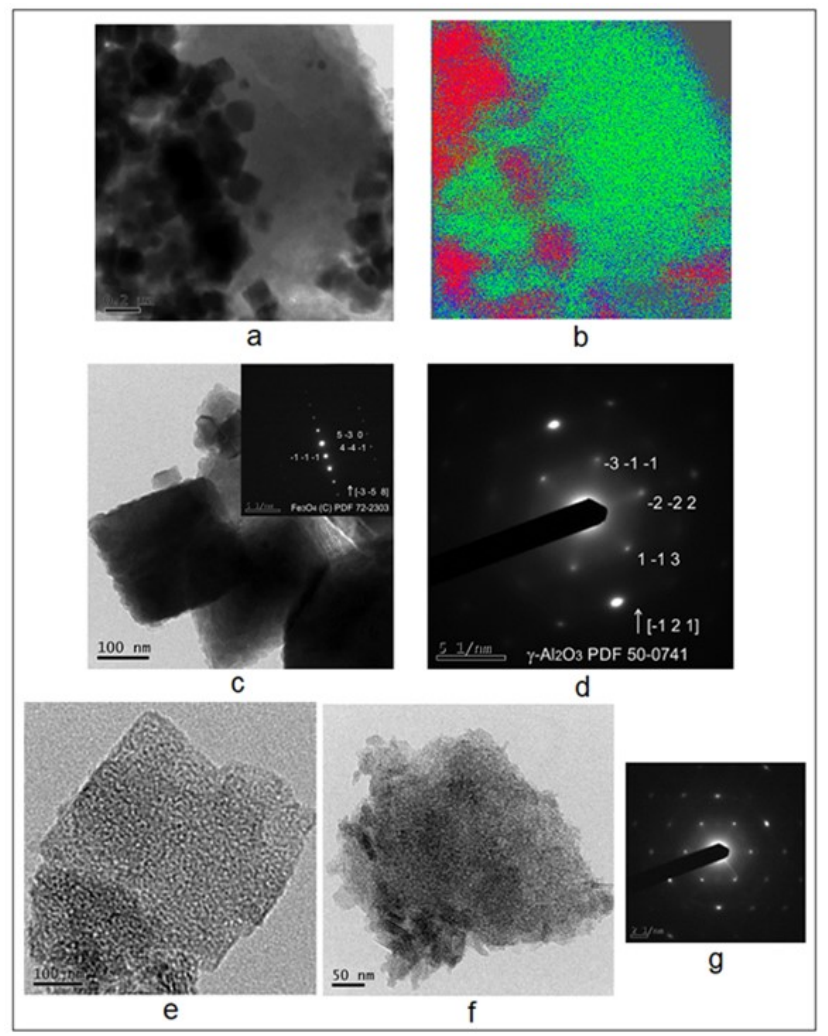

Figure 8. Typical TEM images and SAED patterns of the $\mathrm{Fe}_{3} \mathrm{O}_{4} / \mathrm{Al}_{2} \mathrm{O}_{3}$ interface, a, b -TEM (Bright field) of the $\mathrm{Fe}_{3} \mathrm{O}_{4} / \mathrm{Al}_{2} \mathrm{O}_{3}$ interface and corresponding element mapping ( $\mathrm{Fe}-$ red, Al-green, O-blue); c - typical diffraction of the $\mathrm{Fe}_{3} \mathrm{O}_{4}$ cube; $\mathrm{d}$ - typical diffraction of brighter $\gamma-\mathrm{Al}_{2} \mathrm{O}_{3}$ region; e - platelet of the $\gamma-\mathrm{Al}_{2} \mathrm{O}_{3}$ region; $\mathrm{f}$ - platelets assembly; $\mathrm{g}$ - diffraction of the middle part of the assembly.

The EDS-derived compositions on different nm-sized areas (Figure 10) of the scratched particles reveal a variety of binary $\mathrm{Al} / \mathrm{O}$ and $\mathrm{Fe} / \mathrm{O}$ nanophases and ternary $\mathrm{Al} / \mathrm{Fe} / \mathrm{O}$ nanophases (Table 2), the latter displaying nano-magnetite species attached to adjacent alumina surface. The $\mathrm{Al} / \mathrm{O}$-containing spots correspond to $\mathrm{Al}_{2} \mathrm{O}_{3}$

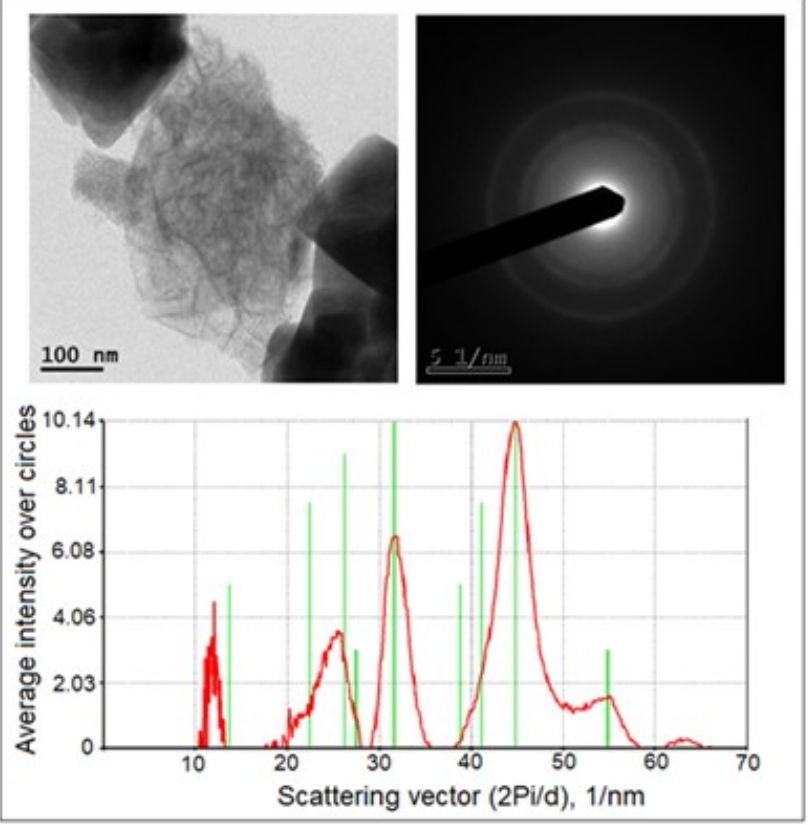

Figure 9. Typical TEM and SAED of the bright alumina region positioned between $\mathrm{Fe}_{3} \mathrm{O}_{4}$ nano-cubes obtained after prolonged ultrasound treatment. Green marker corresponds to $\mathrm{Al}_{2} \mathrm{O}_{3} \mathrm{Pdf}$ 50-0741

or its slightly hydrolyzed form, while the Fe/O- containing spots possess more oxygen than magnetite. Similar increase in $\mathrm{O}$ content is also evident in the $\mathrm{Fe} / \mathrm{Al} / \mathrm{O}$ - containing spots. These stoichiometries and those determined for the water-soaked pristine AAS $\left(\mathrm{AlO}_{1.68-1.89}\right)$ thus indicate hydrolysis of both oxides to species with higher metal valency. Few EDS stoichiometries (locations 1,3,4) may indicate formation of hercynite $\left(\mathrm{FeAl}_{2} \mathrm{O}_{4}\right)$ at $\mathrm{Fe}_{3} \mathrm{O}_{4} / \mathrm{Al}_{2} \mathrm{O}_{3}$ interface, but neither XPS nor diffraction techniques (SAED, XRD) revealed the presence of this form, which implies that possible reactive interaction between alumina surface and $\mathrm{Fe}_{3} \mathrm{O}_{4}$ nanoparticles induced by ultrasound can be excluded.

\subsection{Degradation of antibiotics on AAS and $\mathrm{Fe}_{3} \mathrm{O}_{3}$-coated AAS}

Magnetite is an important catalyst in industry and also in Fenton degradation of water pollutants. ${ }^{[27,28]}$ The catalytic action in the course of which hydrogen peroxide decomposes to highly reactive $\mathrm{OH}$ radical is, however, also reported for alumina ${ }^{[29]}$ and for $\mathrm{Fe}_{3} \mathrm{O}_{4} / \mathrm{Al}_{2} \mathrm{O}_{3}$ catalysts prepared by incipient wetness impregnation of powdered $\mathrm{Al}_{2} \mathrm{O}_{3}{ }^{[30]}$. It was therefore interesting to assess the degradation of a mixture of three recalcitrant antibiotics (trimethoprim (TMP), sulfamethoxazole (SMXZ) and azithromycine (AZMC)) by the washed $\mathrm{Fe}_{3} \mathrm{O}_{4}$-coated 

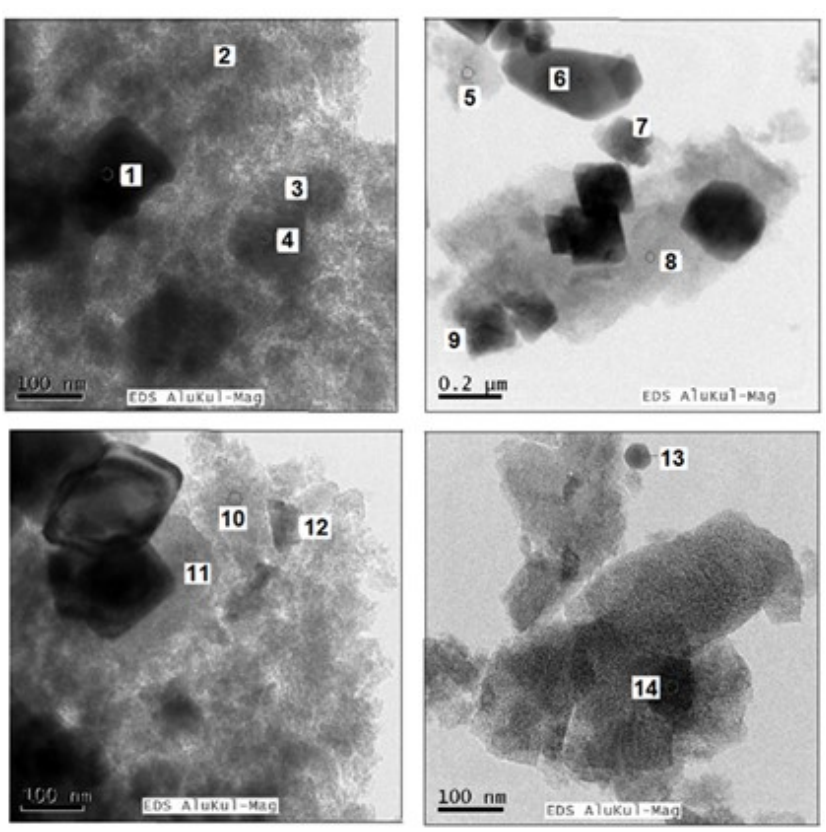

Figure 10. Typical TEM images with locations analyzed by EDS for elemental composition

AAS in the diluted $\mathrm{H}_{2} \mathrm{O}_{2}$ solution. It is observed that concentrations of all the ATB do not decrease in DEI water, but do so in aqueous $\mathrm{H}_{2} \mathrm{O}_{2}$ solution (Figure 11). Such observation is in accordance with negligible if any adsorption of ATB molecules to magnetite and alumina surface and with Fenton degradation of ATB molecules in the $\mathrm{H}_{2} \mathrm{O}_{2}$ solution.

The mass spectral analyses permitted the recognition of degradation paths of TMP in $0.2 \mathrm{M} \mathrm{H}_{2} \mathrm{O}_{2}$ in the presence with the AAS and the washed $\mathrm{Fe}_{3} \mathrm{O}_{4}$-coated AAS. The degradation of TMP with the former spheres is more important (Figure 12) and the positive ions at $\mathrm{m} / \mathrm{z} 355$, $341,307,279,281,277$ relate to demethylation and hy-

Table 2. Some EDS-derived stochiometries at different locations

\begin{tabular}{clcl}
\hline Location & Stoichiometry & Location & Stoichiometry \\
\hline 1 & $\mathrm{AlFe}_{0.58} \mathrm{O}_{2.49}$ & 8 & $\mathrm{AlO}_{1.60}$ \\
2 & $\mathbf{A l O}_{1.52}$ & 9 & $\mathrm{FeAl}_{0.03} \mathrm{O}_{2.34}$ \\
3 & $\mathrm{AlFe}_{0.59} \mathrm{O}_{2.40}$ & 10 & $\mathbf{A l O}_{1.48}$ \\
4 & $\mathrm{AlFe}_{0.42} \mathrm{O}_{2.25}$ & 11 & $\mathrm{FeO}_{1.44}$ \\
5 & $\mathrm{AlO}_{1.75}$ & 12 & $\mathrm{AlFe}_{1.10} \mathrm{O}_{3.88}$ \\
6 & $\mathrm{FeO}_{1.68}$ & 13 & $\mathrm{FeO}_{2.47}$ \\
7 & $\mathrm{FeO}_{2.00}$ & 14 & $\mathbf{A l O}_{\mathbf{1 . 5 0}}$ \\
\hline
\end{tabular}

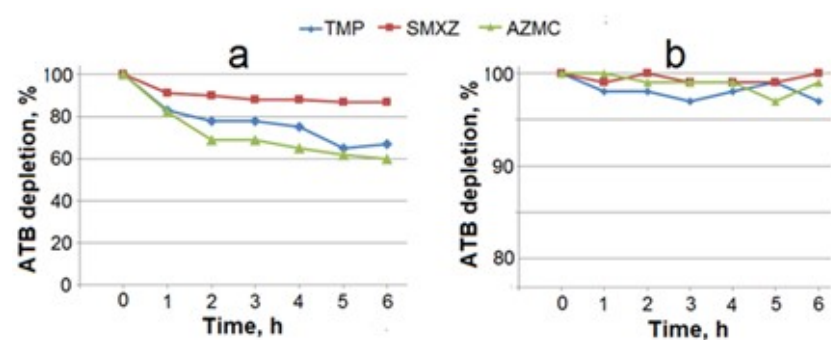

Figure 11. Depletion of ATB in mildly shaken aqueous $0.2 \mathrm{M}$ $\mathrm{H}_{2} \mathrm{O}_{2}$ solution (a) and DEI water (b) containing washed $\mathrm{Fe}_{3} \mathrm{O}_{4}$ coated AAS as dependent on shaking time

droxylation and those at $\mathrm{m} / \mathrm{z} 155,241$ and 139 correspond to cleavage of TMP skeleton. In fact, these ions were also identified for the TMP degradation in $\mathrm{H}_{2} \mathrm{O}_{2}$ solutions under conditions of heterogeneous photocatal$\mathrm{ysis}^{[31,32]}$. The intensities of the ions at $\mathrm{m} / \mathrm{z} 139,141$ and 155 observed with $2 \mathrm{~h}$ shaking are much higher for the coated AAS than for pristine AAS, while these intensities after $4 \mathrm{~h}$ of shaking with the coated and pristine AAS are comparable. These data indicate that TMP degradation is far more feasible on the washed $\mathrm{Fe}_{3} \mathrm{O}_{4}$-coated AAS, whose surface is completely covered by magnetite (as shown by O 1s XP spectra, Figure 6f). The less important TMP degradation on the pristine AAS is, however, also observed and is ascribed to alumina surface.

The above data thus that the TMP degradation is more efficient on the nanomagnetite coat than on the surface of AAS. More laborious analyses of the intensities decay with time are however needed to give a more detailed interpretation. It is seen that the intensities of the $\mathrm{m} / \mathrm{z}$ at 307 observed for the TMP/ $\mathrm{H}_{2} \mathrm{O}_{2}$ solutions in contact with both kinds of spheres are lower than the value for the TMP/ $\mathrm{H}_{2} \mathrm{O}_{2}$ solution without spheres. This surprisingly high intensity of hydroxylated TMP confirms a direct reaction between TMP and $\mathrm{H}_{2} \mathrm{O}_{2}$ and is in line with at least one channel of degradation of TMP induced from TMP-OH.

\section{Conclusions}

Hydration of white activated $\gamma$-alumina is suppressed by ultrasound-dispersed $\mathrm{Fe}_{3} \mathrm{O}_{4}$ nanoparticles which bond to alumina surface in heptane and create black coat permeable to gaseous nitrogen.

This coat is rigid in moving phase of nonpolar alkanes. The coated spheres soaked in still water resist hydration for several weeks, whereas those soaked in moving water release a small portion of $\mathrm{Fe}_{3} \mathrm{O}_{4}$ nanoparticles from outer layers and allow alumina hydration.

The bonding of magnetite nano particles to alumina in 


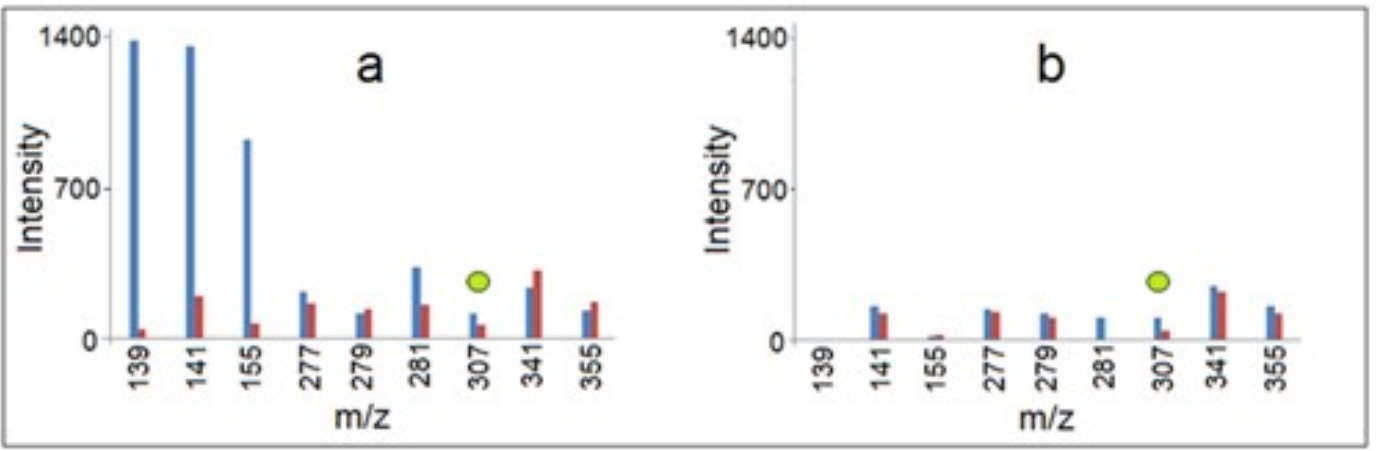

Figure 12. Intensity vs. $\mathrm{m} / \mathrm{z}$ value of fragments detected after 2 and $4 \mathrm{~h}$ (blue and red, respectively) for shaken aqueous $0.2 \mathrm{M}$ $\mathrm{H}_{2} \mathrm{O}_{2}$ solution containing the washed $\mathrm{Fe}_{3} \mathrm{O}_{4}$-coated AAS (a) and pristine AAS (b). Green mark designates intensity at mz 307 for pure $\mathrm{TMP} / \mathrm{H}_{2} \mathrm{O}_{2}$ solution

nonpolar solvent is due to attraction Coulombic forces between these entities.

The sonication permits de-agglomeration and dispersion of $\mathrm{Fe}_{3} \mathrm{O}_{4}$ nanoparticles and induces changes in alumina morphology in regions of contact between alumina and magnetite nanoparticles.

The washed $\mathrm{Fe}_{3} \mathrm{O}_{4}$-coated alumina spheres induce more efficient degradation of recalcitrant antibiotics than the pristine alumina spheres.

\section{Conflicts of Interest}

No potential conflict of interest was reported by the authors.

\section{Acknowledgements}

The authors appreciate partial support of the Technology Agency of the Czech Republic, Program ALFA, project no. TA04020860. The study was also conducted under institutional support from the Institute of Geology of the Czech Academy of Sciences (RVO67985831).

\section{References}

[1] Israelachvili $\mathbf{J}$ and Wennerström $\mathrm{H}$. Role of hydration and water structure in biological and colloidal interactions. Nature, 1996, 379: 219-225. https://doi.org/10.1038/379219a0

[2] Chen H, Cox JR, Ow H, et al. Hydration Repulsion between Carbohydrate Surfaces Mediated by Temperature and Specific Ions. Scientific Reports, 2016, 6: e28553. https://doi.org./10.1038/srep.2016.e28553

[3] Held B, Tang H, Natarajan P, et al. Cucurbit uril inclusion complexation as a supramolecular strategy for color stabilization of anthocyanin model compounds. Photochem Photobiol Sci, 2016, 15: 752-757. https://doi.org./10.1039/c6pp00060f

[4] Kohno Y, Hoshino R, Matsushima R, et al. Stabilization of Flavylium Dyes by Incorporation in the Clay Interlayer.
Journal of the Japan Society of Colour Material, 2007, 80: 6-12.

https://doi.org/10.4011/shikizai1937.80.6

[5] Sullivan RWS (Du Pont Co.). Stabilization of soluble crystalline materials. US Patent 2177269, 1939.

[6] Perrin DD. Covalent Hydration in Nitrogen Heteroaromatic Compounds: II. Quantitative Aspects. Advances in Heterocyclic Chemistry, 1965, 4: 43-73. https://doi.org/10.1016/s0065-2725(08)60874-0

[7] Bunting JW and Perrin DD. 3H-1,2,3,4,6-penta-azaindenes (8-azapurines). Part II. Rates and equilibria for reversible water addition[J]. Journal of the Chemical Society B Physical Organic, 1966: 433.

[8] Eun JH, Lee JH, Kim SG, et al. The protection of MgO film against hydration by using $\mathrm{Al} 2 \mathrm{O} 3$ capping layer deposited by magnetron sputtering method. Thin Solid Films 2003, 435: 199-204. https://doi.org/10.1016/S0040-6090(03)00362-6

[9] Lee BH, Sung MM. Gas-Phase Formation of SelfAssembled Monolayers on $\mathrm{MgO}$ for Protection Against Hydration[J]. Journal of Nanoscience and Nanotechnology, 2008, 8(9): 4818-4821. https://doi.org/10.1166/jnn.2008.IC11

[10] Tadanaga K, Katata N and Minami T. Super-WaterRepellent $\mathrm{Al}_{2} \mathrm{O}_{3}$ Coating Films with High Transparency[J]. Journal of the American Ceramic Society, 1997, 80(4): 1040-1042. https://doi.org/10.1111/j.1151-2916.1997.tb02943.x

[11] Alekseenko LS, Zoz EI, Dyrda NT, et al. The study of structure and stability to hydration of ceramics based on Nd2O3. Russ J Neorg Khim, 1982, 27: 577-581.

[12] Heintz JM, Poix P and Bernier JC. Sintering of $\mathrm{Nd}_{2} \mathrm{O}_{3}$ and ceramic stability to hydration. In Dufour LC et al. (eds.), Surfaces and interfaces of ceramic materials, Kluwer academic publishers, 1989: 565-574.

[13] Posner GH. Organic Reactions at Alumina Surfaces. Angewandte Chemie International Edition in English, 1978, 17(7): 487-496. https://doi.org/10.1002/anie.197804871

[14] Lefevre G, Duc M, Lepeut P, et al. Hydration of g-alumina in water and its effects on surface reactivity. Langmuir, 2002, 18: 7530-7537. https://doi.org/10.1021/la025651i 
[15] Firlar E, Cinar S, Kashyap S, et al. Direct Visualization of the Hydration Layer on Alumina Nanoparticles with the Fluid Cell STEM in situ. Scientific Reports, 2015, 5: 9830. http://doi.org/10.1038/srep09830

[16] Trueba M and Trasatti SP, $\gamma$-Alumina as a Support for Catalysts: A Review of Fundamental Aspects. Cheminform. 2010, 2005(17): 3393-3403. https://doi.org/10.1002/ejic.200500348

[17] Ma W and Brown PW. Mechanisms of Reaction of Hydratable Aluminas[J]. Journal of the American Ceramic Society, 1999, 82(2): 4. https://doi.org/10.1111/j.1551-2916.1999.tb20085.x

[18] JCPDS PDF-4 database, International Centre for Diffraction Data, Newtown Square, PA, USA, release 2016.

[19] Labar JL. Consistent indexing of a (set of) single crystal SAED pattern(s) with the process diffraction program. Ultramicroscopy, 2005, 103: 237-249. http://doi.org/10.1016/j.ultramic.2004.12.004

[20] Knözinger H and Ratnasamy P. Catalytic Aluminas: Surface Models and Characterization of Surface Sites. Catalysis Reviews, 2007, 17(1): 31-70. https://doi.org/10.1080/03602457808080878

[21] Cornell RM and Schwertmann U. The Iron Oxides, Structure, Properties, Reactions, Occurrences and Uses. WileyVCH, 2nd Edition, 2003.

[22] Tombácz E, pH-dependent surface charging of metal oxides. Chem. Engineering 2009, 53: 77-86. https://doi.org/10.3311/pp.ch.2009-2.08

[23] Tombácz E, Hajdú A, Illés E, et al. Water in contact with magnetite nanoparticles, as seen from experiments and computer simulations. Langmuir, 2009, 25: 13007-13014. http://doi.org/10.1021/la901875f

[24] Wang JA, Bokhimi X, Morales A, et al. Aluminum Local Environment and Defects in the Crystalline Structure of SolGel Alumina Catalyst. The Journal of Physical Chemistry B, 1998, 103(2): 299-303. http://doi.org/10.1021/jp983130r
[25] Zhr J, Oswald S, Türpe M, et al. Characterisation of oxide and hydroxide layers on technical aluminum materials using XPS. Vacuum, 2012, 86: 1216-1219. https://doi.org/10.1016/j.vacuum.2011.04.004

[26] Biesinger MC, Payne BP, Grosvenor AP, et al. Resolving surface chemical states in XPS analysis of first row transition metals, oxides and hydroxides: $\mathrm{Cr}, \mathrm{Mn}, \mathrm{Fe}, \mathrm{Co}$ and $\mathrm{Ni}$. Applied Surface Science, 2011, 257(7): 2717-2730. https://doi.org/10.1016/j.apsusc.2010.10.051

[27] He H, Zhong Y, Liang X, et al. Natural Magnetite: an efficient catalyst for the degradation of organic contaminant. Scientific Reports, 2015, 5: 10139. http://doi.org/10.1038/srep10139

[28] Munoz M, De Pedro ZM, Casas JA, et al. Preparation of magnetite-based catalysts and their application in heterogeneous Fenton oxidation A review. Applied Catalysis B: Environmental, 2015, 176-177: 249-265. http://dx.doi.org/10.1016/j.apcatb.2015.04.003

[29] Hiroki A and Laverne JA. Decomposition of Hydrogen Peroxide at Water Ceramic Oxide Interfaces. The Journal of Physical Chemistry B, 2005, 109(8): 3364-3370. http://doi.org/10.1021/jp046405d

[30] Munoz M, De Pedro ZM, Menendez N, et al. A ferromagnetic -alumina-supported iron catalyst for CWPO. Application to chlorophenols. Applied Catalysis B: Environmental, 2013, 136-137(Complete): 218-224. http://dx.doi.org/10.1016/j.apcatb.2013.02.002

[31] Sirtori C, Agüera A, Gernjak W, et al. Effect of water-matrix composition on Trimethoprim solar photodegradation kinetics and pathways. Water Research, 2010, 44: 2735-2744. http://doi.org/10.1016/j.watres.2010.02.006

[32] Cai Q and Hu J. Decomposition of sulfamethoxazole and trimethoprim by continuous UVA/LED/TiO2 photocatalysis: Decomposition pathways, residual antibacterial activity and toxicity. Journal of Hazardous Materials, 2016: S0304389416305611. http://doi.org/10.1016/j.jhazmat.2016.06.006 